\title{
Socio-Demographic, Clinical, and Hygiene Profile of Syndromically Managed Sexually Transmitted Diseases: A Cross Sectional Study in a Tertiary Care Center in India
}

\author{
Darshi Desai*, Erum Khan, Dinesh Rathod \\ Department of Community Medicine, B. J. Medical College, Ahmedabad, India \\ Email: darshidesai100@gmail.com
}

How to cite this paper: Desai, D., Khan, E. and Rathod, D. (2021) Socio-Demographic, Clinical, and Hygiene Profile of Syndromically Managed Sexually Transmitted Diseases: A Cross Sectional Study in a Tertiary Care Center in India. International Journal of Clinical Medicine, 12, 551-569.

https://doi.org/10.4236/ijcm.2021.1212048

Received: October 14, 2021

Accepted: December 11, 2021

Published: December 14, 2021

Copyright $\odot 2021$ by author(s) and Scientific Research Publishing Inc. This work is licensed under the Creative Commons Attribution International License (CC BY 4.0).

http://creativecommons.org/licenses/by/4.0/

\begin{abstract}
Background: Sexually transmitted diseases are one of the several major public health concerns, the burden of which is borne by low- and middle-income countries like India. Purpose: The purpose is to evaluate the relationship between menstrual and sanitary hygiene and sexually transmitted diseases (STD) based on syndromic diagnosis Methods: An out-patient department (OPD) based cross sectional survey to determine these associations, if any exist, which would help critically analyze syndromic management. STD was reported by the presence of vaginal/cervical/urethral discharge with or without irritation and itching, lower abdominal pain and ulcer. Results: The prevalence of STD was $66.84 \%$ with the most commonly reported symptoms being discharged (31.18\%), followed by abdominal pain (17.92\%) and itching/irritation (12.90\%), with ulcer (4.83\%) being the least reported symptom. Perimenopausal age ((AOR: 0.420 [CI: $0.189-0.915] ; p=0.030)$, higher grades of education ((AOR: 0.228 [CI: $0.119-0.424$ ]; $\mathrm{p}<0.001)$ for secondary), urban residency (AOR: 0.435 [CI: $0.686-2.733$ ]; $\mathrm{p}<0.001$ ), and contraception use (AOR: 0.531 [CI: $0.308-0.887$ ]; $\mathrm{p}=0.018$ ) were associated with lesser odds of presenting with an STD symptom. Belonging to a minority religious community (AOR: 7.20 [CI: $1.866-48.251$ ]; $\mathrm{p}<0.012$ ) or backward castes (AOR: 3.753 [CI: $1.587-10.144$ ]; $\mathrm{p}<0.001$ ), having similar illness (AOR: 4.205 [CI: $2.795-6.439$ ]; $\mathrm{p}<0.001$ ) or having an invasive gynecological procedure done in the past one year (AOR: 1.953 [CI: $1.184-3.295$ ]; $\mathrm{p}=$ 0.010 ) and washing the reusable sanitary material only with water (AOR: 4.900 [CI: $2.701-9.116$ ]; $\mathrm{p}<0.001)$ as compared to washing it with water and soap, had a higher association with presenting with STD symptoms. Stratified analysis also showed that women presenting discharge (AOR: 2.049 [CI: 1.343
\end{abstract}


- 3.146] for vaginal and cervical; AOR: 1.426 [CI: 0.826 - 2.482] for urethral) were more likely to not have a toilet facility in an accessible condition. Women with sanitary napkin use had lesser odds (AOR: 0.780 [CI: 0.516 1.180]; $\mathrm{p}=0.293$ ) of presentation for STD in OPD than women who used other material. Conclusion: To better manage the group of diseases that may present with symptoms of STD under syndromic approach, we propose interventions such as menstrual hygiene education and promotion of the use of sanitary napkins among women especially those belonging to lower socio-economic sections of the society.

\section{Keywords}

Sexually Transmitted Diseases, Menstrual Hygiene, Socio-Demographics, Sexually Transmitted Infections, Reproductive Tract Infections, Syndromic Management

\section{Introduction}

Globally, sexually transmitted diseases (STD) have a significant burden on sexual and reproductive health with profound morbidity and mortality. As per the WHO report in 2016, globally there is a 1 million sexually transmitted infections (STIs) are acquired with estimated new cases of 376 million every year [1]. The STI burden varies according to the region and gender and the prevalence is higher in resource-poor countries. The STI is one of the vital public health problems in India and nearly $6 \%$ of the adult population had one or more STI, with an annual incidence of around 30 - 35 million episodes [2].

Adverse complication of curable STIs or STD encompasses pelvic inflammatory disease, infertility, ectopic pregnancy, pregnancy loss, stillbirth, premature rupture of membranes, premature delivery and increased risk of HIV development and transmission and the neonatal outcome includes low birth weight, respiratory depression and increased neonatal ICU admission premature labor and low birth weight [3]. The three major causative pathogens in the progression of curable genital STI are Chlamydia trachomatis, Neisseria gonorrhoeae and Trichomonas vaginalis and they are usually asymptomatic and more commonly observed in females [4].

Due to the lack of skilled healthcare workers at the healthcare facilities and also there is a delay in early diagnosis as a result of expensive and sophisticated instruments which is not available in low-resource settings. So, there is a high chance of misdiagnoses and the infections are not properly treated. In this scenario, the chance of diagnosis is reduced to $50 \%$ and there is a high risk of transmitting the infection and the complications will still remain forever. Thus, the above factors lead to the development of syndromic management. The National AIDS Control Organization (NACO) describes 7 STI syndromes in Women. They are: urethral discharge, cervical discharge, vaginal discharge, ge- 
nital ulcer-non-herpetic, genital ulcer-herpetic lower abdominal pain and inguinal bubo [5].

Previous studies conducted in Pakistan and Namibia report that there is a lack of knowledge among healthcare workers in the syndromic management of STI [6] [7]. In addition, further studies conducted in Pakistan and six countries in West Africa showed decreased knowledge in syndromic management of STI [8] [9]. In another study conducted in Nepal, there is a low level of knowledge among healthcare workers during the management of STI/HIV [10].

Primary care providers orchestrate an important role in the management of STD since various patients with STD are asymptomatic and the infections are diagnosed during their visits in primary care setting. Previous study reports that nearly half of the diagnosed STD is from primary care clinics and nearly $80 \%$ of the STD cases are reported from non-STD clinics [11] [12].

The wide approach to STD/STI also includes some symptoms that may be related to maintenance of menstrual hygiene and adequate wash practices. Our study aimed to find such association, if any, and derive meaningful conclusions as recommendations to improve the syndromic management approach.

\section{Materials and Methods}

This was a cross sectional, observational study conducted in the Obstetrics and Gynecology outpatient department of Civil Hospital, Ahmadabad. Asarwa civil hospital in Ahmedabad is a government hospital tending to needs of the urban and rural population of Ahmedabad district, other parts of Gujarat and referred cases from parts of Rajasthan, Madhya Pradesh and Maharashtra. Our study population covers a broad spectrum of socio-demographic statuses. The patient recruitment was done from February 2019 to June 2019 (20 weeks). We recruited women visiting the gynecology section of the department by consecutive sampling.

Non-pregnant women of reproductive age (18 years and above) attending the OPD with vaginal symptoms (vaginal discharge, itching/irritation/burning, ulcer and lower abdominal pain) were included in the study. Pregnant women, puerperal women and repeating patients were excluded from the study.

\subsection{Sample Size Calculation}

A single proportion sample size estimation formula was used with the following assumptions was used:

$$
n=\left[(Z \alpha / 2)^{2} * p(1-p)\right] / d^{2}
$$

$Z \alpha / 2$ is the standard normal variable value at $95 \% \mathrm{CI}$ (confidence interval) ( $\alpha$ is 0.05 with $95 \% \mathrm{CI}, Z \alpha / 2=1.96$; an estimate of the prevalence $(p)$ of RTI $50 \%$, and $5 \%$ the margin of error $(d)$. A design effect of 1.5 was used due to multistage sampling and a sample size correction formula was employed since the source population was less than 10,000 in the study area. A $10 \%$ non-response rate was 
used to obtain 602 as an adequate sample size.

\subsection{Data Collection}

After identification by the treating physician based on syndromic approach of STD management, all potential study participants underwent an informed consent process in the local language (Gujarati or Hindi) and those choosing to participate provided written consent. Female surveyors administered a comprehensive pre-tested (for validity and reliability) questionnaire immediately after their visit with the attending physician and through it examined risk factors.

The questionnaire was designed by the primary investigators of the study and consists of risk factors in groups of socio-economic characteristics, menstrual hygiene practices and accessibility and usability of toilets for maintaining menstrual hygiene, clinical history and sexual history of subjects. A similar framework was already used by the authors in other related work, as it captures aspects of the working definition of Menstrual hygiene management (MHM) by the Joint Monitoring Program of the WHO and UNICEF in 2012 (defining MHM as: Women and adolescent girls using a clean menstrual management material to absorb blood that can be changed in privacy as often as necessary for the duration of the menstruation period, using soap and water for washing the body as required and having access to facilities to dispose the used menstrual management materials) and also other important risk factors related to the STI identified in the literature.

\subsection{Statistical Analysis}

The data were coded, entered into Microsoft excel 2019, and exported to R statistical analysis software version 4.0.2 used with interface $\mathrm{R}$ studio software for analysis. Descriptive statistics such as frequency distribution and prevalence were computed. Associations between independent variables and STI were determined using a binary logistic regression model.

\section{Results}

Among the 603 patients who visited the gynecology OPD of the hospital during the study period, 558 were enrolled in the study, 13 patients were not willing to participate in the study and 32 patients were excluded from the study.

\subsection{Socio-Demographic Characteristics}

The demographic characteristics of the patients were shown in Table 1. Majority of the patients (67.56\%), were in the age group between 20 - 40 years and the mean age was $32.13 \pm 4.68$ years. Majority of them were married women (73.66\%), followed by unmarried (19.71\%), divorced $(5.20 \%)$ and widowed women $(1.43 \%)$. The majority of women were literate $(80.82 \%)$, Hindu women (62.16\%), belonging to open (66.78\%) category of caste-based reservation system, living in a nuclear family (53.41\%) working as household help or homemaker 
Table 1. Socio-demographic characteristics of the study participants.

\begin{tabular}{|c|c|c|c|c|c|}
\hline \multirow[b]{2}{*}{ Variables } & \multirow{2}{*}{$\begin{array}{c}\text { Frequency } \\
\text { n (\%) }\end{array}$} & \multicolumn{2}{|c|}{ STI } & \multirow[b]{2}{*}{ COR $(95 \% \mathrm{CI})$} & \multirow[b]{2}{*}{$\mathrm{p}$-value } \\
\hline & & $\begin{array}{c}\text { Yes } \\
\text { n }\end{array}$ & $\begin{array}{c}\text { No } \\
\mathrm{n}\end{array}$ & & \\
\hline
\end{tabular}

\section{Age in years}

Less than 20 years

20 - 40 years

More than 40 years

\section{Marital status}

Single
Married
Divorced
Widowed

\section{Religion}

Hindu

Muslim

Others

\section{Educational status}

Illiterate
Primary
Secondary
Higher secondary
Above that

\section{Residence}

Rural

Urban

$\begin{array}{cc}110(19.71 \%) & 73 \\ 411(73.66 \%) & 269 \\ 29(5.20 \%) & 25 \\ 8(1.43 \%) & 6\end{array}$

345 (62.16\%)

179 (32.25\%)

$31(5.59 \%)$

237

104

29

$\begin{array}{cc}107(19.18 \%) & 84 \\ 176(31.54 \%) & 107 \\ 164(29.39 \%) & 87 \\ 95(17.02 \%) & 81 \\ 16(2.87 \%) & 14\end{array}$

169 (30.29\%)

389 (69.71\%)

94

279

\section{Occupation}

Homemaker/Housemaker
Laborer
Other

$353(63.37 \%) \quad 237$

$89(15.98 \%) \quad 53$

$115(20.65 \%)$

82

Income of self

Less than Rs.5000 per month

More than Rs.5000 per month

$356(63.80 \%)$

227

$202(36.20 \%)$

146

129

56

$0.675(0.459-0.991) \quad 0.041^{*}$

\section{Family status}

\begin{tabular}{llcccc} 
Nuclear & $298(53.41 \%)$ & 193 & 105 & 1 & \\
Joint & $160(28.67 \%)$ & 126 & 34 & $0.495(0.314-0.783)$ & $0.002^{*}$ \\
\hline
\end{tabular}




\begin{tabular}{lccccc} 
Continued & $100(17.92 \%)$ & 54 & 46 & $1.566(0.979-2.502)$ & 0.0558 \\
\hline Others & & & & & \\
Caste & $372(66.78 \%)$ & 239 & 133 & 1 & \\
Open & $125(22.44 \%)$ & 80 & 45 & $(0.103-0.546)$ & $<0.001^{*}$ \\
SC/ST/OBC & $60(10.77 \%)$ & 53 & 7 & 0.237 & 0.960 \\
Others &
\end{tabular}

1: Reference category. Illiterate stands for not having attended both formal and informal education, primary education means Grade 1 - 8; secondary education means Grade 9 - 10, higher secondary means Grade $=10-12$, and graduate education means having acquired a diploma, degree, masters and others.

(63.37\%) earning less than 5000 per month (63.80\%). The categories of housewife and household help were taken together in occupation as the objective of study was accessibility of an inhouse toilet or separate space dedicated to maintenance of hygiene.

The prevalence of sexually transmitted disease on basis of syndromic approach among reproductive-age women was $66.84 \%$ [CI: 62.76 - 70.74]. The most commonly reported symptoms were vaginal/cervical discharge (31.18\%), followed by abdominal pain (17.92\%) and urethral discharge/irritation/itching (12.90\%) and ulcer (4.83\%).The symptoms which were not considered as STD according to syndromic approach included gynecological symptoms like pain or discomfort during intercourse, bleeding between periods, frequent and urgent need to urinate, or a burning sensation during urination, abnormal vaginal bleeding, particularly during or after intercourse, pain or pressure in pelvis that differs from menstrual cramps etc. They were present in $33.15 \%$ of the patients.

\subsection{Availability and Usage of Toilet}

Among the patients recruited in the study, a clean, isolated, toilet facility with presence of water was available to $48.38 \%$. No significant association of this parameter was obtained with chief complain of STD according to syndromic management, however stratified analysis of each of the complaints showed that there were higher odds of not having access to such a facility among women presenting with discharge (COR: 2.049 [CI: 1.343 - 3.146]; p < 0.001) and itching/irritation (COR: 1.426 [CI: $0.826-2.482$ ]; $\mathrm{p}=0.204$ ). The results are shown in Table 2.

\subsection{Past Clinical History}

In our study, 79.75\% women reported not having an invasive gynecological procedure (like abortion/dilation and curettage etc.) in the past 1 year. However, those who had undergone a procedure showed higher odds (COR-1.655 [CI: $1.046-2.683] ; \mathrm{p}=0.035)$ of reporting an STD symptom as compared to reporting other symptoms. A positive history of similar illness was reported by $55.91 \%$ participants. Patients with STD symptoms were thrice as likely as other patients to have experienced similar illness (COR: 3.358 [CI: $2.291-4.988$ ]; $\mathrm{p}<0.001$ ). 
Among participants, $80.107 \%$ did not report per vaginal exam done in the last year and $68.41 \%$ of married women living with their husbands, denied concomitant presence of STD symptoms in their partners. The results were shown in Table 3.

Table 2. Availability and usage of toilet among study participants.

\begin{tabular}{|c|c|c|c|c|c|}
\hline \multirow[b]{2}{*}{ Variables } & \multirow{2}{*}{$\begin{array}{c}\text { Frequency } \\
\text { n (\%) }\end{array}$} & \multicolumn{2}{|c|}{ STI } & \multirow[b]{2}{*}{ COR $(95 \% \mathrm{CI})$} & \multirow[b]{2}{*}{ p-value } \\
\hline & & $\begin{array}{c}\text { Yes } \\
\mathrm{n}\end{array}$ & $\begin{array}{c}\text { No } \\
\text { n }\end{array}$ & & \\
\hline \multicolumn{6}{|l|}{ Availability and usage of toilet } \\
\hline Used & $270(48.38 \%)$ & 174 & 96 & & \\
\hline Unused & $288(51.61 \%)$ & 199 & 89 & $1.234(0.867-1.757)$ & 0.244 \\
\hline \multirow{2}{*}{ Frequency of chief complain } & \multicolumn{3}{|c|}{ Availability and usage of toile } & & \\
\hline & & Used & Unused & & \\
\hline Vaginal/Cervical Discharge & $174(31.18 \%)$ & 60 & 114 & $2.049(1.343-3.146)$ & $<0.001^{\star}$ \\
\hline Abdominal pain & $100(17.92 \%)$ & 68 & 32 & $0.507(0.302-0.839)$ & $<0.009^{\star}$ \\
\hline Ulcer & $27(4.83 \%)$ & 15 & 12 & $0.863(0.376-1.940)$ & 0.722 \\
\hline Urethral discharge/itching/irritation & $72(12.90 \%)$ & 31 & 41 & $1.426(0.826-2.482)$ & 0.204 \\
\hline Other chief complain- not related to RTI & $185(33.15 \%)$ & 96 & 89 & 1 & \\
\hline
\end{tabular}

1: Reference category.

Table 3. Obstetrics and Gynecological history among the study population

\begin{tabular}{|c|c|c|c|c|c|}
\hline \multirow[b]{2}{*}{ Variables } & \multirow{2}{*}{$\begin{array}{c}\text { Frequency } \\
n(\%)\end{array}$} & \multicolumn{2}{|c|}{ STI } & \multirow[b]{2}{*}{ COR $(95 \% \mathrm{CI})$} & \multirow[b]{2}{*}{$\mathrm{p}$-value } \\
\hline & & $\begin{array}{c}\text { Yes } \\
n\end{array}$ & $\begin{array}{c}\text { No } \\
n\end{array}$ & & \\
\hline \multicolumn{6}{|c|}{ History of abortion/D and C/Other invasive procedures in year prior to data collection } \\
\hline Yes & $113(20.25 \%)$ & 85 & 28 & $1.655(1.046-2.683)$ & $0.035^{\star}$ \\
\hline No & $445(79.75 \%)$ & 288 & 157 & 1 & \\
\hline \multicolumn{6}{|c|}{ History of similar symptoms in year prior data collection } \\
\hline Yes & $246(44.08 \%)$ & 199 & 47 & $3.358(2.291-4.988)$ & $<0.001^{\star}$ \\
\hline No & $312(55.91 \%)$ & 174 & 138 & 1 & \\
\hline \multicolumn{6}{|l|}{ Per Vaginal exam in the past year } \\
\hline Yes & $111(19.892 \%)$ & 75 & 36 & $1.012(0679-1.310)$ & 0.798 \\
\hline No & $447(80.107 \%)$ & 286 & 161 & 1 & \\
\hline \multirow{2}{*}{ Husband's illness of reproductive tract } & \multicolumn{4}{|c|}{ Multiple sexual partners } & \\
\hline & & Yes & No & & \\
\hline Yes & $145(31.59 \%)$ & 80 & 28 & $0.752(0.499-1.778)$ & 0.166 \\
\hline No & $314(68.41 \%)$ & 21 & 429 & 1 & \\
\hline
\end{tabular}

1: Reference category. 


\subsection{Behavioral Factors}

The majority (91.22\%) of the study participants did not have multiple sexual partners during the previous year. The bivariate analysis showed that those respondents who had multiple sexual partners were at a higher risk for developing STD (COR: 1.136 [CI: $0.613-2.202$ ]; $\mathrm{p}=0.692$ ) compared to those who did not have multiple partners. Majority of women reported having their first experience of sexual intercourse during ages 25 - 35 years (59.35\%). The odds of presenting with an STD complain were significantly higher (three times) in women who had experienced sexual intercourse than those who had not. The women who had their first sexual intercourse at ages between 25 and 35 years had the highest odds of presenting with an STD (COR: 2.883 [CI: 1.754 - 4.762]; p < 0.001). The use of contraception, though seen only in $19.35 \%$ of women was significantly associated with having lesser odds of presenting with STD symptoms (COR: 0.546 [CI: $0.332-0.897$ ]; $\mathrm{p}=0.0149$ ). The results were shown in Table 4 .

\subsection{Menstrual Hygiene Management (MHM) and Washing Practices}

Unfortunately, the majority of women recruited in the study did not use sanitary napkins $(66.13 \%)$. Out of all women, $31.69 \%$ denied re-using their menstrual absorbent material. $28.69 \%$ of women reused the material and changed the material twice a day, followed by once a day $(26.23 \%)$ and more than twice a day (13.38\%). However, $61.44 \%$ participants used only water to wash it. The use of sanitary napkins had lesser odds (COR: 0.742 [CI: $0.510-0.981$ ]; $p=0.041$ ) of presenting with STD symptoms in the OPD. As the frequency of washing increased, the odds of presenting with STD complain decreased. For those reusing

Table 4. Characteristics of behavioral factors among study participants.

\begin{tabular}{|c|c|c|c|c|c|}
\hline \multirow[b]{2}{*}{ Variables } & \multirow[b]{2}{*}{$\begin{array}{c}\text { Frequency } \\
n(\%)\end{array}$} & \multicolumn{2}{|c|}{ STI } & \multirow[b]{2}{*}{ COR $(95 \% \mathrm{CI})$} & \multirow[b]{2}{*}{$\mathrm{p}$-value } \\
\hline & & $\begin{array}{c}\text { Yes } \\
n\end{array}$ & $\begin{array}{c}\text { No } \\
n\end{array}$ & & \\
\hline \multicolumn{6}{|c|}{ Multiple sexual partners during the last year } \\
\hline Yes & $49(8.78 \%)$ & 34 & 15 & $1.136(0.613-2.202)$ & 0.692 \\
\hline No & $509(91.22 \%)$ & 339 & 170 & 1 & \\
\hline \multicolumn{6}{|l|}{ Age at first sexual intercourse } \\
\hline Not yet & $81(14.56 \%)$ & 38 & 43 & 1 & \\
\hline Less than 25 years & $106(19.06 \%)$ & 70 & 36 & $2.200(1.220-4.007)$ & $<0.001^{\star}$ \\
\hline 25 - 35 years & $330(59.35 \%)$ & 227 & 103 & $2.883(1.754-4.762)$ & $<0.001^{\star}$ \\
\hline More than 35 years & $39(7.01 \%)$ & 21 & 18 & $2.880(1.292-6.770)$ & $0.011^{*}$ \\
\hline \multicolumn{6}{|c|}{ Use of any kind of contraception } \\
\hline Yes & $108(19.35 \%)$ & 83 & 25 & $0.546(0.332-0.897)$ & $0.0149^{*}$ \\
\hline No & $450(80.64 \%)$ & 290 & 160 & 1 & \\
\hline
\end{tabular}

1: Reference category. 
Table 5. Menstrual hygiene management (MHM) practices among reproductive age women.

\begin{tabular}{|c|c|c|c|c|c|}
\hline \multirow[b]{2}{*}{ Variables } & \multirow{2}{*}{$\begin{array}{c}\text { Frequency } \\
n(\%)\end{array}$} & \multicolumn{2}{|c|}{ STI } & \multirow[b]{2}{*}{ COR $(95 \% \mathrm{CI})$} & \multirow[b]{2}{*}{ p-value } \\
\hline & & $\begin{array}{c}\text { Yes } \\
n\end{array}$ & $\begin{array}{c}\text { No } \\
n\end{array}$ & & \\
\hline \multicolumn{6}{|c|}{ Nature of absorbent material used during menstruation } \\
\hline Cloth/cotton equivalent & $369(66.13 \%)$ & 255 & 114 & 1 & 0.749 \\
\hline Sterile sanitary pad/napkin & $189(33.87 \%)$ & 118 & 71 & $0.742(0.510-0.981)$ & $0.041^{*}$ \\
\hline \multicolumn{6}{|l|}{ Frequency of washing the material } \\
\hline I do not wash it as I do not reuse it & $116(31.69 \%)$ & 69 & 47 & 1 & \\
\hline Once per day & $96(26.23 \%)$ & 21 & 75 & $2.430(1.339-4.505)$ & $0.004^{*}$ \\
\hline 2 times per day & $105(28.69 \%)$ & 74 & 29 & $1.736(0.940-2.45)$ & 0.054 \\
\hline More than 2 times per day & $49(13.38 \%)$ & 34 & 15 & $1.542(0.759-3.929)$ & 0.229 \\
\hline \multicolumn{6}{|l|}{ Wash Material } \\
\hline Water and soap & $96(38.55 \%)$ & 53 & 43 & 1 & \\
\hline Water only & $153(61.44 \%)$ & 131 & 22 & $4.618(2.589-8.418)$ & $<0.001^{\star}$ \\
\hline
\end{tabular}

the material, washing only with water had higher odds of presenting with an STD in OPD (COR: 4.618 [CI: 2.589 - 8.418]; $\mathrm{p}<0.001$ ). The results were shown in Table 5 .

\subsection{Multivariable Logistic Regression Analysis}

The results of multivariable logistic regression analysis of demographic profile of patients are shown in Table 6. We found that socio-demographic factors like perimenopausal age (more than 40 years) had significantly lesser odds of presenting with STD complain (AOR: 0.420 [CI: $0.189-0.915$ ]; $\mathrm{p}=0.03$ ), having a primary and secondary education had significantly lesser odds of presenting with STD complain ((AOR: 0.275 [CI: 0.144 - 0.510]; p < 0.001) and (AOR: 0.228 [CI: $0.119-0.424$ ]; $\mathrm{p}<0.001)$ respectively), living in hostels, dormitories or individually had lesser odds (AOR: 0.542 [CI: $0.309-0.944$ ]; $\mathrm{p}<0.031$ )) of presenting with STD symptoms and so did living in urban areas (AOR: 0.435 [CI: 0.686 - 2.733]; $\mathrm{p}<0.001)$. Belonging to a religion other than Hinduism or Islam (AOR: 7.20 [CI: $1.866-48.251$ ]; $\mathrm{p}=0.012$ ) and a caste other than open/ST/SC had a higher odd (AOR: 3.753 [CI: $1.587-10.144$ ]; $\mathrm{p}<0.001$ ) of presenting with STD symptoms.

The results of multivariable logistic regression analysis of clinical profile of patients are shown in Table 7 . Women who had similar illness in the past were 4 times more likely to present with STD symptoms (AOR: 4.205 [CI: 2.795 6.439]; $\mathrm{p}<0.001)$. Having a history of an invasive gynecological procedure raised the odds to twice (AOR: 1.953 [CI: 1.184 - 3.295]; $\mathrm{p}=0.010$ ). Among those who had had sexual intercourse, the age group of less than 35 years was at higher odds of presenting with STD symptoms ( $\mathrm{p}<0.001)$. 
Table 6. Factors associated with STDs among reproductive age women from multivariable logistic regression analysis - Demographics.

\begin{tabular}{|c|c|c|c|}
\hline Variable & COR $(95 \% \mathrm{CI})$ & AOR $(95 \% \mathrm{CI})$ & p-value of AOR \\
\hline \multicolumn{4}{|l|}{ Age } \\
\hline Less than 20 years & 1 & 1 & \\
\hline $20-40$ years & $2.21(1.15-4.29)$ & $1.127(0.569-2.199)$ & 0.727 \\
\hline More than 40 years & $1.01(0.56-1.86)$ & $0.420(0.189-0.915)$ & $0.030^{*}$ \\
\hline \multicolumn{4}{|l|}{ Education } \\
\hline Illiterate & 1 & 1 & \\
\hline Primary & $1.235(0.13-1.413)$ & $0.275(0.144-0.510)$ & $<0.001^{\star}$ \\
\hline Secondary & $0.323(0.184-0.568)$ & $0.228(0.119-0.424)$ & $<0.001^{\star}$ \\
\hline Higher secondary & $0.631(0.299-1.331)$ & $0.108(0.047-0.255)$ & 0.844 \\
\hline Graduate & $0.521(0.107-2.541)$ & $0.258(0.058-1.836)$ & 0.258 \\
\hline \multicolumn{4}{|l|}{ Residence } \\
\hline rural & 1 & 1 & \\
\hline urban & $0.494(0.107-2.542)$ & $0.435(0.686-2.733)$ & $<0.001^{\star}$ \\
\hline \multicolumn{4}{|l|}{ Income } \\
\hline Less than 5000 & 1 & 1 & \\
\hline More than 5000 & $0.675(0.459-0.991)$ & $0.846(0.535-1.333)$ & 0.471 \\
\hline \multicolumn{4}{|l|}{ Family } \\
\hline nuclear & 1 & 1 & \\
\hline Joint/extended & $1.566(0.979-2.502)$ & $1.815(1.094-3.094)$ & 0.052 \\
\hline Others (dorms, hostels, individual) & $0.495(0.314-0.783)$ & $0.542(0.309-0.944)$ & $0.031^{*}$ \\
\hline \multicolumn{4}{|l|}{ Caste } \\
\hline Open & 1 & 1 & \\
\hline $\mathrm{SC} / \mathrm{ST}$ & $(0.546-0.103)$ & $1.105(0.655-1.888)$ & 0.708 \\
\hline $\mathrm{OBC}$ and other minorities & 0.237 & $3.753(1.587-10.144)$ & $<0.001^{\star}$ \\
\hline \multicolumn{4}{|l|}{ Religion } \\
\hline Hindu & 1 & 1 & \\
\hline Muslim & $0.631(0.434-0.919)$ & $0.433(0.274-0.678)$ & $<0.1$ \\
\hline Others & $6.607(1.943-41.34)$ & $7.20(1.866-48.251)$ & $<0.012^{\star}$ \\
\hline
\end{tabular}

1: Reference category.

The results of multivariable logistic regression analysis of sanitation practices among are shown in Table 8 . Among the practices that determined hygiene, not having a toilet and using material other than sanitary napkin had higher odds of presenting with symptoms of STD ((AOR: 1.109 [CI: 0.745 - 1.647]; p = 0.611) and (AOR: 0.780 [CI: $0.516-1.180] ; \mathrm{p}=0.293$ ) respectively) however they were 
Table 7. Factors associated with STDs among reproductive age women from multivariable logistic regression analysis-Clinical and Sexual history.

\begin{tabular}{|c|c|c|c|}
\hline Variable & COR $(95 \% \mathrm{CI})$ & AOR $(95 \% \mathrm{CI})$ & p-value \\
\hline \multicolumn{4}{|c|}{ Similar illness in the past 1 year } \\
\hline Yes & $3.358(2.291-4.988)$ & $4.205(2.795-6.439)$ & $<0.001^{*}$ \\
\hline No & 1 & 1 & \\
\hline \multicolumn{4}{|c|}{ History of abortion/DNC/other invasive procedure } \\
\hline Yes & $1.655(1.046-2.683)$ & $1.953(1.184-3.295)$ & $0.010^{*}$ \\
\hline No & 1 & 1 & \\
\hline \multicolumn{4}{|l|}{ Contraception use } \\
\hline yes & $0.546(0.332-0.897)$ & $0.531(0.308-0.887)$ & $0.018^{\star}$ \\
\hline no & 1 & 1 & \\
\hline \multicolumn{4}{|c|}{ Age at first sexual intercourse } \\
\hline Not yet & 1 & 1 & \\
\hline Less than 25 years & $2.200(1.220-4.007)$ & $2.941(1.552-5.661)$ & $<0.001^{*}$ \\
\hline $25-35$ years & $2.883(1.754-4.762)$ & $3.073(1.791-5.320)$ & $<0.001^{*}$ \\
\hline More than 35 years & $2.880(1.292-6.770)$ & $2.307(0.981-5.680)$ & 0.060 \\
\hline
\end{tabular}

1: Reference category.

Table 8. Factors associated with STDs among reproductive age women from multivariable logistic regression analysis-MHM and toilet facility.

\begin{tabular}{llll}
\hline Variable & COR $(95 \% \mathrm{CI})$ & AOR $(95 \% \mathrm{CI})$ & p-value of AOR \\
\hline $\begin{array}{l}\text { Toilet availability and usage } \\
\text { Yes }\end{array}$ & 1 & 1 & 0.611 \\
No & $1.234(0.867-1.757)$ & $1.109(0.745-1.647)$ & \\
Material used during menstruation & & & 1 \\
$\quad$ Cotton/Cloth & 1 & $0.780(0.516-1.180)$ & 0.293 \\
$\quad$ Sanitary napkin & $0.742(0.510-0.981)$ & & \\
\hline
\end{tabular}

1: Reference category.

not statistically significant $((\mathrm{p}=0.611$ and $\mathrm{p}=0.293)$ respectively).

The results of multivariable logistic regression analysis of menstrual hygiene and wash practices of patients are shown in Table 9. As the frequency of washing increased the odds of presenting with an STD decreased however it was not a significant decrease. Usage of water only for washing reusable material was associated with four times greater odds of presenting with STD symptoms (AOR: 4.900 [CI: $2.701-9.116] ; \mathrm{p}<0.001)$.

\section{Discussion}

The prevalence of STD symptoms in the present study is 66.84 which is 
Table 9. Factors associated with RTIs among reproductive age women from multivariable logistic regression analysis- MHM and wash material.

\begin{tabular}{|c|c|c|c|}
\hline Variable & $\operatorname{COR}(95 \% \mathrm{CI})$ & AOR $(95 \% \mathrm{CI})$ & p-value \\
\hline \multicolumn{4}{|c|}{ Wash frequency for women not using sanitary napkins } \\
\hline Do not reuse & 1 & Not included in multiple regression model & \\
\hline Wash once a day & $2.430(1.339-4.505)$ & 1 & \\
\hline Wash twice a day & $1.736(0.940-2.45)$ & $0.771(0.387-1.520)$ & 0.454 \\
\hline Wash more than twice a day & $1.542(0.759-3.929)$ & $0.821(0.359-1.906)$ & 0.641 \\
\hline \multicolumn{4}{|l|}{ Material used for wash } \\
\hline Water and soap & 1 & 1 & \\
\hline Water only & $4.83(2.606-8.9551)$ & $4.900(2.701-9.116)$ & $<0.001^{*}$ \\
\hline
\end{tabular}

1: Reference category. 
careless unprotective sex.

In the present study, women working as a laborer had a higher odd of presenting with an STD to the OPD (COR: 1.387; [CI: $0.85-2.26$ ]; $\mathrm{p}=0.179$ ). This could be due to lesser access of toilet facility for women who work as laborer. Women presenting with vaginal/cervical discharge were twice more likely and others with urethral discharge with or without itching and irritation were 1.43 times more likely to not have accessibility to a usable toilet facility ( $p<0.001$ and $\mathrm{p}=0.204)$. This finding highlights the magnitude of difference that can be achieved with the promotion of clean toilet facility in reducing the STD burden in households.

The fact that females presenting with similar symptoms in the past 1 year were more likely to present with STD symptoms shows that there is a possibility of presence of a habit/ chronically unchanging practice that contributed to STD symptoms significantly. We also found that a history of STI symptoms in the year before data collection was significantly associated with the development of STI. A similar study in an urban training health center of a tertiary care hospital in India showed that STI was significantly associated with a history of STIs in the previous year [12]. We found that women with invasive procedures done in the past one year were more likely to present with STI symptoms. A similar study among women in urban slums of India showed that participants who had a history of abortion had higher odds of STI symptoms than those who had no history of abortion [24].

Das et al. [25] reported that Indian women using disposable absorbent pads were less likely to develop infections than women using reusable material, consistent with our study suggesting that women who used sanitary napkins had lesser ((OR: 0.742); $\mathrm{p}=0.041)$ odds of presenting with an STD and it was not significant. The literature reports that poor sanitation may facilitate transmission where genital contact is made with infected genital fluids on the latrine toilet seat [26]. A study conducted in Dehradun, India, reported an association between STI and poor menstrual hygiene as measured by washing the genitalia less often than twice per day during menstruation [27]. Among the women who did not use sanitary napkins, our study had women who used no-reusable/disposable cotton and women who used cloth and reused them after washing. The women who used cloth had higher odds of presenting with STD symptoms than women who used cotton.

\section{Limitations}

Our study had several limitations. Some of the crude associations when reanalyzed after stratification lost their significance which may be due to the decrease in stratified sample population. We did not report women who were laboratory confirmed cases of STDs. Furthermore, the results of this study may not be representative of the occurrence and underlying factors of STDs at the national level because it was conducted only in Ahmedabad. 
Future studies should include a wider population sample and confirm the suspected STD cases with laboratory findings to better determine the cohort of women who may present with STD symptoms according to syndromic diagnosis but actually suffer from diseases related to improper menstrual and sanitary hygiene.

\section{Conclusion}

STI is a preventable illness that does affect the public health of the country. There still exists a barrier in the physician-patient discussion regarding sexual acts, safe sex practices and menstrual hygiene. Ever since the concept of treating STI based on syndromic approach has been proposed, the focus has shifted from eliminating the root cause of the disease to symptomatic management. Syndromic approach has effectively treated women from STI, however, it does not reduce incidence of STI as the factors that promote transmission still exist widely in the community. Although our study cannot conclude a causal relationship between unhygienic MHM practices and STI, it highlights the need for a safe, hygienic and comfortable environment for women for MHM practices, so as to reduce the colonization of sexually transmitted pathogens and thereby, reduce the risk of STI.

\section{Recommendations}

In low- and middle-income countries, for the ease of management of STDs, syndromic approach has been in place. Our study highlights important associations of STD symptoms with socioeconomic conditions and menstrual and sanitary hygiene. With small additions in the execution of syndromic management of STD a wider group of diseases can be dealt with.

In line with significant association of complains of discharge with toilet availability, we recommend ensuring hygienic places for women, particularly those belonging to low socioeconomic backgrounds and promoting its use to practice MHM. Since our study also found a crude association between the use of cotton/cloth as sanitary material and presentation with an STD symptom to OPD, we recommend that a menstrual hygiene education and if we may be too ambitious, a supply of sanitary pads should be made available to women presenting with STD symptoms. To arrest the spread of STI, it is necessary to educate the people regarding the factors that increase transmission and prevalence. Our study has stated the factors that affect the risk of acquisition of STI and the areas that our country's jurisdiction must prioritize while framing health policies. It is certainly every woman's right to practice safe MHM and it is the need of the hour to extend the public health rationale to also cover the reproductive and sexual health of the women.

\section{Conflicts of Interest}

The authors declare no conflicts of interest regarding the publication of this paper. 


\section{References}

[1] Rowley, J., Vander, H.S., Korenromp, E., Low, N., Unemo, M., Abu-Raddad, L.J., et al. (2019) Global and Regional Estimates of the Prevalence and Incidence of Four Curable Sexually Transmitted Infections in 2016. WHO Bulletin, World Health Organization, Geneva.

[2] Patel, N. and Mazumdar, V. (2019) The Current Status of Sexually Transmitted Infections/Reproductive Tract Infections in Vadodara City: Health-Care Provider Perspective. Indian Journal of Community Medicine, 44, 247-251. https://doi.org/10.4103/ijcm.IJCM_382_18

[3] Ademas, A., Adane, M., Sisay, T., Kloos, H., Eneyew, B., Keleb, A., et al. (2020) Does Menstrual Hygiene Management and Water, Sanitation, and Hygiene Predict Reproductive Tract Infections among Reproductive Women in Urban Areas in Ethiopia? PLoS ONE, 15, Article ID: e0237696. https://doi.org/10.1371/journal.pone.0237696

[4] Detels, R., Green, A.M., Klausner, J.D., Katzenstein, D., Gaydos, C., Handsfield, H.H., et al. (2011) The Incidence and Correlates of Symptomatic and Asymptomatic Chlamydia trachomatis and Neisseria gonorrhoeae Infections in Selected Populations in Five Countries. Sexually Transmitted Diseases, 38, 503-509. https://doi.org/10.1097/OLQ.0b013e318206c288

[5] Krishnamurthy, D.D., Sivagnaname, D.Y., Yasodha, D.S. and Karthika, D.K. (2019) Study of Syndromic Management of Sexually Transmitted Infections in Women of Reproductive Age at a Tertiary Care Hospital in Tamil Nadu, India. Obs Gyne Review: Journal of Obstetric and Gynecology, 5, 231-236.

https://doi.org/10.17511/joog.2019.i05.04

[6] Hussain, M.F.A., Khanani, M.R., Siddiqui, S.E., Manzar, N., Raza, S. and Qamar, S. (2011) Knowledge, Attitudes \& Practices (KAP) of General Practitioners (GPS) Regarding Sexually Transmitted Diseases (STDS) and HIV/AIDS in Karachi, Pakistan. Journal of Pakistan Medical Association, 61, 202-205.

[7] Iipinge, S.N. and Pretorius, L. (2012) The Delivery and Quality of Sexually Transmitted Infections Treatment by Private General Practitioners in Windhoek Namibia. Global Journal of Health Science, 4, 156-171. https://doi.org/10.5539/gjhs.v4n5p156

[8] Khan, A.A. and Khan, A. (2012) Sexually Transmitted Infection Care in Pakistan: The Providers Perspective. Journal of the Pakistan Medical Association, 62, 941-945. https://pubmed.ncbi.nlm.nih.gov/23139980/

[9] Bitera, R., Alary, M., Mâsse, B., Viens, P., Lowndes, C., Baganizi, E., et al. (2012) Quality of Disease Management of Sexually Transmitted Diseases: Investigation of Care in Six Countries in West Africa. Sante, 12, 233-239. https://pubmed.ncbi.nlm.nih.gov/12196297/

[10] Adhikari, C., Sherchan, L., Thapa, S. and Adhikari L. (2014) Effectiveness of Syndromic STI Case Management/RH Training in Knowledge and Practice of Auxiliary Health Workers. Journal of Universal College of Medical Sciences, 2, 34-37. https://doi.org/10.3126/jucms.v2i3.11826

[11] Brackbill, R.M., Sternberg, M.R. and Fishbein, M. (1999) Where Do People Go for Treatment of Sexually Transmitted Diseases? Family Planning Perspectives, 31, 10-15. https://doi.org/10.2307/2991551

[12] Sexton, J., Garnett, G. and Røttingen, J.-A. (2005) Meta-Analysis and Metaregression in Interpreting Study Variability in the Impact of Sexually Transmitted Diseases on Susceptibility to HIV Infection. Sexually Transmitted Diseases, 32, 351-357. 
https://doi.org/10.1097/01.olq.0000154504.54686.d1

[13] Gawande, K.B., Srivastava, A.S. and Kumar, P. (2018) Reproductive Tract Infection and Health Seeking Behaviour: A Cross Sectional Community Based Study. International Journal of Community Medicine and Public Health, 5, 1524-1528. https://doi.org/10.18203/2394-6040.ijcmph20181229

[14] Ratnaprabha, G.K., Thimmaiah, S., Johnson, A. and Ramesh, N. (2015) Prevalence and Awareness of Reproductive Tract Infections among Women in Select Underprivileged Areas of Bangalore City. International Journal of Medical Science and Public Health, 4, 1691-1696. https://doi.org/10.5455/ijmsph.2015.15052015349

[15] Thekdi, K., Patel, K., Patel, N. and Thekdi, P. (2014) A Cross Sectional Study on the Prevalence of Reproductive Tract Infections amongst Married Women in the Rural Area of Surendranagar District. International Journal of Research in Medical Sciences, 2, 215-221. https://doi.org/10.5455/2320-6012.ijrms20140242

[16] Bhilwar, M., Lal, P., Sharma, N., Bhalla, P. and Kumar, A. (2015) Prevalence of Reproductive Tract Infections and Their Determinants in Married Women Residing in an Urban Slum of North-East Delhi, India. Journal of Natural Science, Biology and Medicine, 6, 29-34.

[17] Rani, V., Dixit, A.M., Kumar, S., Singh, N.P. and Jain, P.K. (2016) Reproductive Morbidity Profile among Ever Married Women (15-44) Years of Rural Etawah District, Uttar Pradesh: A Cross-Sectional Study. National Journal of Community Medicine, 7, 35-40.

[18] Kamini, B. and Srisanthanakrishnan, V. (2017) A Study on Prevalence of Reproductive Tract Infections among Women in a Rural Area of Tamil Nadu. International Journal Of Community Medicine And Public Health, 5, 336-340. https://doi.org/10.18203/2394-6040.ijcmph20175809

[19] Mansor, N., Ahmad, N. and Rahman, H.A. (2020) Determinants of Knowledge on Sexually Transmitted Infections among Students in Public Higher Education Institutions in Melaka State, Malaysia. PLoS ONE, 15, Article ID: e0240842. https://doi.org/10.1371/journal.pone.0240842

[20] Ayerdi Aguirrebengoa, O., Vera Garcia, M., Rueda Sanchez, M., D’Elia, G., Chavero Méndez, B., Alvargonzalez Arrancudiaga, M., et al. (2020) Risk Factors Associated with Sexually Transmitted Infections and HIV among Adolescents in a Reference clinic in Madrid. PLoS ONE, 15, e0228998. https://doi.org/10.1371/journal.pone.0228998

[21] Torondel, B., Sinha, S., Mohanty, J.R., Swain, T., Sahoo, P., Panda, B., et al. (2018) Association between Unhygienic Menstrual Management Practices and Prevalence of Lower Reproductive Tract Infections: A Hospital-Based Cross-Sectional Study in Odisha, India. BMC Infectious Diseases, 18, Article No. 473.

https://doi.org/10.1186/s12879-018-3384-2

[22] Griffiths, M. and David, N. (2013) Sexually Transmitted Infections in Older People. International Journal of STD \& AIDS, 24, 756-757. https://doi.org/10.1177/0956462413488768

[23] Crichton, J., Hickman, M., Campbell, R., Batista-Ferrer, H. and Macleod, J. (2015) Socioeconomic Factors and Other Sources of Variation in the Prevalence of Genital Chlamydia Infections: A Systematic review And Meta-Analysis. BMC Public Health, 15, Article No. 729. https://doi.org/10.1186/s12889-015-2069-7

[24] Pandit, M. and Nagarkar, A. (2017) Determinants of Reproductive Tract Infections among Women in Urban Slums of India. Women's Reproductive Health, 4, 106-114. https://doi.org/10.1080/23293691.2017.1326251 
[25] Das, P., Baker, K.K., Dutta, A., Swain, T., Sahoo, S., Das, B.S., et al. (2015) Menstrual Hygiene Practices, WASH Access and the Risk of Urogenital Infection in Women from Odisha, India. PLoS ONE, 10, Article ID: e0130777. https://doi.org/10.1371/journal.pone.0130777

[26] Muual, D. and Geubbels, E. (2007) Epidemiology of Reproductive Tract Infections (RTIs) in Malawi. Malawi Medical Journal, 18, 176-190. https://doi.org/10.4314/mmj.v18i4.10921 http://www.ajol.info/index.php/mmj/article/view/10921

[27] Juyal, R., Kandpal, S.D. and Semwal, J. (2014) Menstrual Hygiene and Reproductive Morbidity in Adolescent Girls in Dehradun, India. Bangladesh Journal of Medical Science, 13, 170-174. https://doi.org/10.3329/bjms.v13i2.14257 https://www.banglajol.info/index.php/BJMS/article/view/14257 


\section{Questionnaire}

Sr. Number:

Initials:

Chief complaint:

1. Age (in years):

2. Residence:

o Rural

o Urban

3. Education:

o Literate

o Illiterate

If literate, level of education acquired or acquiring:

o Primary

o Secondary

o higher secondary

o Graduate

o post graduate

4. Occupation:

5. Income: Monthly Income of the Patient:

Total monthly income of the family:

6. Family:

o Nuclear

o Joint

7. Caste:

o Open

o SC

o ST

o OBC

8. Religion:

9. Marital Status:

o Unmarried

o Married

o Separated

o Divorced

o Widow

If married:

For how many years have you stayed with your husband?:

At present, are you staying with your husband?: Yes/No

10. Husband's occupation:

11. What was your age at first sexual intercourse:

12. Do you have more than one sexual partners: Yes/No

13. Do you use Contraception: Yes/No

If yes, Which one?: Condom /IUD/OC Pills/permanent sterilisation/others 
14. During menstruation, which material do you use?

o Sanitary napkin

o Cloth

o Others

If cloth:

Do you reuse it? Yes/No

If Yes,

How do you wash it?

o With water only

o With water and soap

How frequently do you wash it?

15. Is there a toilet in your home? Yes/No

16. How many times have you undergone per vaginal examinations in the past 1 year?

17. Did you have a delivery/ abortion in the past 1 year?: Yes/No If Yes-Delivery/Abortion

18. Have you experienced similar illness in the past 1 year? Yes/No If Yes,

How many times?

Did you visit a doctor immediately?: Yes/No

If No?: Reason:

19. Does your husband have a similar illness at present?

20. Has your husband experienced similar illness in the past 1 year? Yes/No If yes, what was it?: Ulcer/Discharge/others 